\title{
Cuándo deberían los utilitaristas ser teóricos de la virtud*
}

\author{
DALE JAMIESON \\ New York University
}

\begin{abstract}
RESUMEN. El contraste que habitualmente se establece entre el Utilitarismo y la teoría de la virtud queda en entredicho en este ensayo. El Utilitarismo puede encarnar cualquier conducta, ya que implica que deberíamos mentir, engañar, robar y aun apropiarnos de Aristóteles, si con ello vamos a ocasionar los mejores resultados. En algunas situaciones y en algunos mundos posibles, lo mejor se obtendría centrándonos en los rasgos de carácter. El Cambio Medioambiental Global nos lleva al estudio de los caracteres, puesto que en este caso los mejores resultados se obtienen, generalmente, al disociar nuestro comportamiento del de los demás. Por ello, en este caso y en este mundo, los utilitaristas deberían ser teóricos de la virtud.
\end{abstract}

ABSTRACT. The contrast typically between utilitarianism and virtue theory is overdrawn. Utilitarianism in a universal emulator: it implies that we should lie, cheat, steal, even appropriate Aristotle, when that is what brings about the best outcomes. In some cases and in some worlds it is best for us to be concerned with character traits. Global environmental change leads to concerns about character because the best results will be produced by generally uncoupling my behaviour from that of others. Thus, in this case an in this case an in this world, utilitarians should be virtue theorist.

1. Comenzaremos con una aserción que muy pocos rechazarían, pero ante la cual muchos cierran los ojos: los seres humanos están transformando la Tierra de un modo que resulta devastador para otras formas de vida, para los seres humanos del futuro e incluso para muchos de los actuales. La epidemia de extinciones que estamos viviendo muestra con claridad este hecho. Del mismo modo que lo hace el cambio climático. La progresiva reducción de la capa de ozono, que continúa produciéndose a un altísimo ritmo es, potencialmente, el resultado más letal de estas transformaciones, ya que sin capa de ozono la vida sobre la Tierra no podría existir. A partir de ahora, llamaremos a las extinciones en masa provocadas por los seres humanos, al

\footnotetext{
* Traducción: Roberto Feltrero (IFS, CSIC) y Paula Olmos (UNED).

Isegoría quiere agradecer a Carmen Velayos (Universidad de Salamanca) su generosa coordinación de la parte monográfica del presente número.
} 
cambio climático y a la reducción de la capa de ozono, el «Problema del Cambio Medioambiental Global» (o el «Problema, para abreviar) ${ }^{1}$.

2. En gran medida, los filósofos, en el desempeño de sus funciones profesionales, han guardado silencio sobre el Problema. Y ello por muchos motivos. Creo que uno de ellos es precisamente la dificultad de dar una respuesta desde la perspectiva de las teorías éticas dominantes: el Kantismo, el Contractualismo, y el Pluralismo del Sentido común ${ }^{2}$. Aunque la extensión de este artículo no me permita justificar por completo esta afirmación, ofreceré algunas consideraciones que pueden ayudar a hacer comprensible mi interés en explorar las posibles soluciones utilitaristas al Problema.

3. Consideremos, en primer lugar, el Kantismo. Christine Korsgaard afirma que «no es casual» que los utilitaristas estén «obsesionados» con el «control demográfico» y «la protección del medioambiente» ${ }^{3}$. Pues existe «un rasgo fundamental de la perspectiva consecuencialista que aún hoy invade y distorsiona nuestro modo de pensar: la idea de que el cometido de la moralidad es producir algo [sic]» ${ }^{4}$. Korsgaard da a entender que una teoría moral correctamente concebida tendría poco que decir sobre el medioambiente, ya que tal teoría rechazaría como falsa esta caracterización del «cometido de la moralidad». Semejante impresión se ve reforzada por el hecho de que esta observación sobre las obsesiones medioambientales de los utilitaristas resulta ser la única alusión al medioambiente en un libro de más de cuatrocientas páginas ${ }^{5}$.

No resulta sorprendente que un punto de vista que renuncia a la cuestión de qué resultados debemos obtener como perteneciente al «cometido de la moralidad» se encuentre desarmada a la hora de pensar en cómo responder al Cambio Medioambiental Global. El silencio del Kantismo sobre este tema está relacionado con dos rasgos básicos de la teoría: el individualismo y el énfasis en «lo interno». Algunos filósofos kantianos han intentado superar,

1 Aunque «Cambio Medioambiental Global» pueda parecer una expresión torpe o confusa, se ha convertido en el modo convencional de referirse a este conjunto de problemas en la literatura científica y en los textos legales; véase, p. ej., la página web de The Encyclopedia of Global Environmental Change (http://www.wiley.co.uk/wileychi/egec/). Para una visión general de estos problemas véase el documento World Resources 2000-2001 elaborado por el Instituto de Recursos Mundiales, el Programa de Naciones Unidas para el Medio Ambiente y el Banco Mundial (New York, Elsevier Science, 2000), también disponible en http://wristore.com/worres20.html.

2 Hay quien modificaría este listado de las teorías éticas dominantes añadiendo, o sustituyendo por alguno de los anteriores, el Neo-Contractualismo o la Teoría de Virtud.

${ }^{3}$ Creating the Kingdom of Ends, Nueva York, Cambridge University Press, 1996, p. 300.

4 Ibid., p. 275. Cf. Annette Baier que piensa que los filósofos morales contemporáneos aún no han logrado escapar de las garras de Kant, Postures of the Mind, Minneapolis, University of Minnesota Press, 1985 , p. 235.

5 Sin embargo, Korsgaard se refiere brevemente al status moral de plantas y animales en The Sources of Normativity, Nueva York, Cambridge University Press, 1996, cap. 4, y discute ampliamente el punto de vista kantiano sobre los animales en su conferencia «Tanner» de la Universidad de Michigan, «Fellow Animals: Kantian Ethics and Our Duties to Animals», disponible en http://www.people.fas.harvard.edu/ korsgaar/CMK.FellowCreatures.pdf. 
al menos, el individualismo de la teoría, pero resulta difícil, ya que estos dos rasgos están estrechamente relacionados ${ }^{6}$. Kant no estaba tan interesado en las acciones simpliciter como en las fuentes de las que manan. Pero cuando nuestro objetivo prioritario reside en determinar cómo debemos actuar frente al Cambio Medioambiental Global, necesitamos una teoría que se ocupe seriamente de lo que las personas provocan, más que una teoría que esté (digamos) «obsesionada» por la pureza de la voluntad ${ }^{7}$.

4. El Contractualismo presenta dificultades tanto a la hora de abordar los problemas ambientales, en general, como el Cambio Medioambiental Global, en particular, por, al menos, tres razones. En primer lugar, porque tal teoría se encuentra normalmente en aprietos al enfrentarse a problemas de cooperación a gran escala y a las cuestiones sobre la confianza que éstos suscitan. En segundo lugar, el Contractualismo tampoco es capaz de dar cuenta de las «externalidades» negativas, p. ej., las consecuencias que tiene para mí el hecho de que dos adultos se pongan voluntariamente de acuerdo para producir y consumir sustancias que contaminan el ambiente. En principio, sería posible superar estos problemas acometiendo algunas modificaciones en el núcleo de la teoría. Pero el problema más profundo del Contractualismo reside en la exclusión de toda consideración moral sobre aquellos que no han participado en los acuerdos relevantes ${ }^{8}$. Y, sin embargo, muchas de nuestras preocupaciones medioambientales se centran precisamente en aquellos que las condiciones de esta aproximación teórica excluyen: las generaciones futuras, las personas pertenecientes a comunidades remotas, los niños, los animales, etc.

5. El Pluralismo del Sentido común está limitado por su conservadurismo intrínseco ${ }^{9}$. Aunque los pluralistas del sentido común condenen moralmente las formas más evidentes de mal comportamiento, en última instancia se encuentran comprometidos con la idea de que la mayoría de nuestras acciones son perfectamente aceptables. El papel de la filosofía moral consis-

${ }^{6}$ Véase, por ejemplo, los intentos de Onora O'Neill en su colección de artículos Constructions of Reason: Explorations of Kant's Practical Philosophy, Nueva York, Cambridge University Press, 1989. Korsgaard trata, por su parte, de superar el «internalismo» de la teoría considerando como el núcleo temático de la moralidad «el modo en que deberíamos relacionarnos los unos con los otros», op. cit., p. 275.

7 Algunas interpretaciones de Kant, quizás la más notable sea la de R. M. Hare. Véase, Freedom and Reason, Oxford, Oxford University Press, 1965, enfatizan la idea de la «universabilidad», en detrimento de la noción de «buena voluntad». No es ésta la interpretación de Kant que nos ocupa ahora, en parte porque ha perdido influencia en los últimos años, pero también porque (al menos en lo referente al asunto que tratamos) vendría a oscurecer la distinción entre Kantismo y Utilitarismo.

${ }^{8}$ Ello queda claro en el trabajo de, por ejemplo, David Gauthier y Jan Narveson. Hace algún tiempo discutí estos problemas en «Rational Egoism and Animal Rights», Environmental Ethics, 3, verano de 1981, pp. 67-71.

${ }^{9}$ Aunque existan muchas diferencias y desacuerdos entre sus partidarios, algunos de los cuales no aceptarían la acusación de conservadurismo, me estoy refiriendo al punto de vista de filósofos británicos como Jonathan Dancy y Stuart Hampshire, y americanos como Susan Wolf. 
te, fundamentalmente para ellos, en la explicación y justificación de nuestras creencias morales y nuestras actitudes cotidianas, más que en una seria evaluación de las mismas. Desde este punto de vista, critican al Utilitarismo por su excesivo celo corrector y a los utilitaristas por no tener ninguna gracia ${ }^{10}$. Pero aquello que produce el Cambio Medioambiental Global es precisamente nuestro comportamiento diario que es, aparentemente, inocente desde la perspectiva del sentido común: construir una bonita casa de campo, ir en coche a recoger a los niños al colegio y, desde luego, tenerlos, por mencionar solamente algunos ejemplos ${ }^{11}$. Para el modelo teórico del sentido común, cualquier teoría moral que prescriba un determinado comportamiento que evite o minimice el Cambio Medioambiental Global, será escandalosamente correccionista.

6. Hay quien diría que las teorías de la moralidad dominantes tienen poco que decir sobre nuestro Problema, precisamente porque no lo consideran un problema moral. Sin duda, el cambio climático (por ejemplo) conlleva toda una serie de importantes e interesantes desafíos de carácter tanto científico como práctico, pero ello no lo convierte en un problema moral ${ }^{12}$.

La cuestión sobre lo que pertenece (o no) al ámbito de la moralidad es en sí un tema de gran importancia e interés y merecedor de un amplio tratamiento, sin embargo, me limitaré a ofrecer unas pocas observaciones al respecto. Puede que los defensores de las teorías deontológicas no consideren el Cambio Medioambiental Global como un problema moral, porque, bajo su punto de vista, los problemas morales se reducen a aquello que intencionalmente queremos producir, y nadie tiene la intención de provocar el Cambio Medioambiental Global ${ }^{13}$. De modo similar, los kantianos, que niegan que «el cometido de la moralidad consista en producir algo», pueden también

10 Las posturas anti-correccionistas se pueden encontrar en diferentes versiones, una de las cuales se puede encontrar en la introducción de Judith Jarvis Thomson, The Realm of Rights, Cambridge MA, Harvard University Press, 1990; para el segundo aspecto, véase Susan Wolf, «Moral Saints», Journal of Philosophy, 79, 1982, pp. 419-439, especialmente p. 422. Para una respuesta utilitarista a tales acusaciones, véase Peter Singer, How Are We To Live? Ethics in an Age of SelfInterest, Buffalo NY, Prometheus Books, 1995.

11 Sobre las consecuencias medioambientales de las costumbres reproductivas de los norteamericanos, véase Charles A.S. Hall, R. Gil Pontius Jr., Lisa Coleman y Jae-Young Ko, «The Environmental Consequences of Having a Baby in the United States», Wild Earth 5, 2, verano de 1995 , pp. 78-87.

12 Cabría hacer varias matizaciones a este respecto. Jürgen Habermas afirma que «la responsabilidad de los seres humanos para con las plantas y la conservación de las especies no puede derivarse de sus obligaciones, que emanan de sus propias interacciones, y en consecuencia [sic] no pueden justificarse moralmente», pero continúa diciendo que «existen buenas razones éticas para defender la protección de plantas y especies». Véase su Justification and application: Remarks on Discourse Ethics, Ciaran Cronin (trad.), Cambridge, The MIT Press, 1993, p. 111.

13 Para una discusión más amplia de la deontología y el papel de las intenciones en la configuración de las constricciones morales, consultar: Nancy (Ann) Davis, "Contemporary Deontology», en Peter Singer (ed.), A Companion to Ethics, Oxford, Basil Blackwell, 1991, pp. 205-218, y también la bibliografía allí citada. 
tener sus razones para excluir nuestro Problema del ámbito de la moralidad. Pero independientemente del punto de vista «oficial» sobre lo que compete a la moralidad, lo cierto es que la cuestión sobre cómo deberíamos regular nuestro comportamiento ante el cambio climático, la reducción de la capa de ozono, y las extinciones en masa es importante para todo aquel que se preocupe por la naturaleza o por el bienestar de los seres humanos -y tales preocupaciones se han considerado tradicionalmente cercanas al núcleo de la reflexión moral-.

7. A nuestros efectos, presupondremos que nuestro Problema es un problema moral. Estudiaremos este Problema bajo el punto de vista utilitarista porque el Utilitarismo, al centrarse sin complejos en el producto de nuestras acciones se encuentra en una inmejorable posición para ofrecer respuestas interesantes a nuestro Problema. Es más, puesto que el Utilitarismo se compromete con la idea de que la moralidad nos exige producir el mejor mundo posible, y el Cambio Medioambiental Global presenta desproporcionadas consecuencias nocivas, no es posible sustraerse al hecho de que, para los utilitaristas, el Cambio Medioambiental Global supone un problema moral urgente, complejo y de gran alcance.

Sin embargo, me gustaría pensar que este proyecto podría resultar interesante incluso para aquellos que no son utilitaristas militantes. Para cualquier teoría moral plausible, las consecuencias deberían importar. El Utilitarismo lleva al límite el interés por las consecuencias, y siempre resulta interesante ver hasta dónde nos lleva la versión más pura de cualquier doctrina. Además, creo que deberíamos considerar a las grandes tradiciones de la filosofía moral más como programas de investigación que como teorías acabadas que implican o sustentan determinados dogmas. Por esta razón resulta interesante comprobar hasta qué punto una determinada tradición moral es capaz de dar cuenta de problemas que no fueron previstos por sus creadores ${ }^{14}$.

8. Mientras Korsgaard critica al Utilitarismo por sus obsesiones medioambientales, muchos filósofos preocupados por el medioambiente ven, en cambio, en el Utilitarismo una doctrina que favorece el consumo por encima de la conservación. En concreto, a los utilitaristas se les ha acusado de preferir tarimas de secuoya a las propias secuoyas y las cajas de palillos a los bosques centenarios. Otros filósofos medioambientales argumentan que el Utilitarismo no puede por sí mismo dar cuenta del valor de la diversidad biológica, de los ecosistemas o de las especies en vías de extinción, y a continuación rechazan la teoría por su extensión del ámbito de «lo sintiente» y lo moral. De acuerdo con estos críticos, más que ofrecernos una nueva ética

${ }^{14}$ Espero que quede claro que mi intención hasta el momento se ha limitado a mostrar que, en primer término y comparado con sus rivales, el Utilitarismo parte de una buena posición para dar respuesta al Problema y, por ello, merece ser explorado con detalle. No obstante, no pretendo sugerir que otras visiones alternativas no tengan recursos para ofrecer respuestas interesantes a nuestro Problema. 
medioambiental, lo que hasta ahora ha hecho la teoría utilitarista es llevarnos al borde de la destrucción ${ }^{15}$.

Pero el Utilitarismo posee una importante ventaja a menudo ignorada por sus críticos: nos obliga a que hagamos lo mejor. Por eso no puede tener éxito ninguna objeción que se limite a afirmar que el Utilitarismo nos obliga a hacer algo que no es lo mejor, o incluso que ni siquiera es bueno. Cualquier acción o política que produzca consecuencias que no sean óptimas, no sería siquiera capaz de satisfacer el principio de utilidad. Cualquier teoría que prescriba la realización de tales acciones no puede ser utilitarista ${ }^{16}$.

Tal como yo concibo el Utilitarismo, se trata de una teoría que nos obliga moralmente a que realicemos acciones dirigidas a producir los mejores resultados. No se compromete con ninguna afirmación explícita sobre qué hace que un resultados sea bueno, ni sobre qué hace que algo cuente como resultado y ni siquiera sobre qué hace que algo sea una acción ${ }^{17}$. El hecho es que contar con buenas respuestas teóricas a estas preguntas no implica que vayamos siempre a saber lo que está bien a la hora de tomar decisiones prácticas. Incluso aunque pensemos que ya sabemos lo que está bien, siempre podríamos cambiar de opinión a la luz de la reflexión, del análisis, o de la experiencia. Si el Utilitarismo es verdadero, adoptar tal teoría podría ser el primer paso para llegar a hacer lo que está bien, aunque ciertamente no será el último ${ }^{18}$.

9. El Utilitarismo es una teoría moral sumamente sensible al contexto. Por lo tanto, ya que pretendo explicitar cómo debería responder un utilitarista a un problema moral actual, necesitaré simplificar el punto de partida, de manera que me permita ofrecer respuestas más explícitas que «eso depen-

15 Para tales críticas véase J. Baird Callicott, «Animal Liberation: A Triangular Affair», Environmental Ethics, 2, 1980, pp. 311-338; Holmes Rolston III, «Respect for Life: Counting what Singer Finds of no Account», en Dale Jamieson (ed.), Singer and His Critics, Oxford, Blackwell, 1999; Eric Katz, Nature as Subject, Lanham, MD, Rowman and Littlefield, 1997; John Rodman, «The Liberation of Nature», Inquiry, 20, 1977, pp. 83-131, y Mark Sagoff, «Animal Liberation and Environmental Ethics: Bad Marriage, Quick Divorce», Osgood Hall Law Journal, 22, 2, 1984, pp. $297-307$

16 Cf. Korsgaard, quien con acierto señala que «generalmente las "objeciones estándar" que una escuela de pensamiento esgrime contra otra, incurren en el fondo y de manera disimulada en una petición de principio», op. cit., p. xiii.

17 En esta caracterización del Utilitarismo, coincido con Liam Murphy, Moral Demands in Nonideal Theory, Nueva York, Oxford University Press, 2000, p. 6, más que con Shelly Kagan que utiliza el término «consecuencialismo» para lo que yo denomino Utilitarismo; véase su análisis en Normative Ethics, Boulder CO, Westview Press, 1998. Para una discusión más amplia sobre el uso de estos términos, véase mi entrada «Consequentialism», en el artículo «Ethics and Values» de la Encyclopedia of Life Support Systems (EOLSS), editada por R. Elliot y publicada bajo el patrocinio de la UNESCO, Oxford, EOLSS Publishers, 2002, disponible en http://www.eolss.net.

18 De hecho puede que no sea ni siquiera el primer paso. Puede incluso que la teoría utilitarista implique que el utilitarismo deba ser una «moralidad esotérica». El hecho de que implique o no tal cosa dependerá de las afirmaciones específicas realizadas sobre los individuos y sobre las sociedades. Para un análisis sobre la «moralidad esotérica» véase Henry Sidgwick, The Methods of Ethics, Londres, Macmillan, 1907, p. 490, y Derek Parfit, Reasons and Person, Nueva York, Oxford University Press, 1984, Parte Primera (especialmente el cap. 1). 
de». En lo que sigue, presupondré que el sujeto utilitarista en cuestión sostiene opiniones bastante generalizadas y razonablemente tradicionales sobre los asuntos mencionados en el párrafo anterior (p. ej., que el bienestar es, al menos, una de las cosas que están bien, o que el hecho de que yo sea la causa de que algo ocurra o se dé es, en parte, lo que hace que algo pueda considerarse el resultado de mi acción, etc.). También supondré que, consideradas en conjunto, estas opiniones implican que, a fin de cuentas, el Cambio Medioambiental Global es algo malo (o al menos no lo mejor). Además, asumiré que el utilitarista en cuestión es una persona cuya forma de pensar es similar a la mía, y que tenemos aproximadamente las mismas creencias acerca de la configuración del mundo. No pretendo con ello afirmar nada extraordinario - sólo que, por ejemplo, nuestra toma de decisiones no se ve afectada de manera decisiva por la creencia de que este mundo es solamente un campo de entrenamiento para pasar a otro posterior, o que la mayor parte de los líderes mundiales son agentes de una conspiración alienígena, o que es tan plausible que yo sea un cerebro en una cubeta como un tipo con empleo. Con estas presuposiciones, y ante el Cambio Medioambiental Global, el sujeto utilitarista se enfrentaría a la siguiente pregunta: ¿Cómo debería conducirme en mi vida diaria para producir los mejores resultados?

10. Para responder esta pregunta, algo que deberíamos tener en cuenta es que el Cambio Medioambiental Global se nos presenta como el mayor de los problemas de acción colectiva a nivel mundial. Ningún individuo actuando en solitario podría producir o evitar las consecuencias nefastas que entre todos producimos. Es más, el Cambio Medioambiental Global a menudo se manifiesta de forma indirecta. Los efectos del cambio climático (por ejemplo) incluyen la subida del nivel de mar, una mayor frecuencia de las sequías, de las tormentas y de las temperaturas extremas. Estos efectos pueden dar lugar a una escasez de alimentos o de agua, a epidemias y a transformaciones en las estructuras económicas, políticas y sociales ${ }^{19}$. En última instancia, el resultado podría ser la muerte de millones de personas, pero el cambio climático nunca será la causa de la muerte inscrita en un certificado de defunción. Puesto que nuestras acciones individuales no son decisivas en lo que concierne a los resultados globales, y estamos protegidos tanto geográfica como temporalmente de sus efectos, muchos no creen que su comportamiento tenga algo que ver con la aparición de tales consecuencias ${ }^{20}$.

19 Para consultar el más reciente, autorizado y sistemático recuento de las consecuencias del cambio climático, véase James J. McCarthy, Osvaldo F. Canziani, Neil A. Leary, David J. Dokken y Kasey S. White (eds.), Climate Change 2001: Impacts, Adaptation \& Vulnerability, Nueva York, Cambridge University Press, 2001, disponible en http://www.ipcc.ch/. Véase también mi artículo «The Epistemology of Climate Change: Some Morals for Managers», Society and Natural Resources, 4, 1991, pp. 319-329.

${ }^{20}$ Sobre este tema véase Jonathan Glover, «'It Makes No Difference Whether Or Not I Do It'», reimpreso en Peter Singer (ed.), Applied Ethics, Nueva York, Oxford University Press, pp. 125-144; y op. cit., cap. 3. 
Por otro lado, las personas que sí se consideran implicadas en la producción de estos resultados nefastos, a menudo no saben cómo responder a la situación y ni siquiera tienen claro qué puede razonablemente exigírseles.

Para un utilitarista, al menos queda claro lo siguiente: los agentes deberían reducir al mínimo su contribución al Cambio Medioambiental Global y actuar de tal modo que induzcan a los demás a minimizar la suya. Con todo, y al menos en principio, estas dos obligaciones pueden considerarse independientes. Es posible que la mejor estrategia para un agente utilitarista resulte ser la hipocresía: podría, de hecho, resultar que, para reducir al máximo la contribución global, fuera necesario aumentar su propia contribución al Problema (por ejemplo, porque el éxito de la causa ecologista dependa de una serie de viajes en avión por todo el mundo para promoción de la misma). O quizás resulte ser el Ascetismo: tal vez el no prestar atención más que su propia contribución sea el modo más efectivo de minimizar el monto total de contribuciones al Problema. Puede que algunos agentes utilitaristas crean que cualquiera de estas estrategias es mejor que alguna otra de carácter «mixto». Sin embargo, es plausible suponer que para la mayoría los agentes utilitaristas, en casi todas las circunstancias, la estrategia más eficaz implicaría tanto acciones encaminadas a reducir al mínimo sus propias contribuciones, como otras destinadas a provocar que los otros reduzcan al mínimo las suyas ${ }^{21}$. Todo ello parece deducirse naturalmente (aunque no lógicamente) del hecho de que somos animales sociales con una gran influencia sobre los demás y muy permeables a la influencia de los otros.

11. A la luz de estas consideraciones, ¿cómo debería vivir un sujeto utilitarista para hacerse cargo del Problema? Creo que uno de los rasgos necesarios en cualquier propuesta adecuada sería la «incondicionalidad» (NonContingency). La incondicionalidad obliga a los agentes actuar de tal forma que se minimice su contribución al Cambio Medioambiental Global, y especifica que tal actuación no debería estar condicionada por las creencias del agente sobre el comportamiento de los demás. El argumento a favor de la incondicionalidad se deriva del fracaso de la consideración del Problema desde el punto de vista de la «condicionalidad» (Contingency). Desde un punto de vista utilitarista, tal condicionalidad implicaría un sofisticado cálculo para obtener un resultado satisfactorio. Pero resulta que, en problemas

${ }^{21}$ Ya que tales estrategias pueden implicar tanto la creación como la transmisión de normas, creo que nada de lo que aquí se dice resulta incompatible con el análisis de Philip Pettit sobre las normas como respuestas a los problemas de acción colectiva en la parte III de Rules, Reasons and Norms, Oxford, Oxford University Press, 2002. Un modo de conciliar nuestros puntos de vista sería afirmar que el análisis que estoy realizando incluye una descripción relativamente densa de cómo debería ser un agente utilitarista para que pudieran surgir las normas adecuadas y, a la vez, reducir su propia contribución al Problema. En lo que sigue, me centro principalmente en las acciones de agentes individuales, primero porque el argumento podría generalizarse a todo agente utilitarista en las mismas condiciones, y segundo, porque creo que en muchas exposiciones teóricas se subestima la importancia de los agentes individuales al tratar de los problemas colectivos (véase la Sección 19 para una más amplia discusión). 
de acción colectiva a gran escala, dicho cálculo daría como actitudes resultantes la locura o el cinismo - la locura, porque es imposible ser consciente de la suma total de las acciones, y el cinismo porque parece que tanto la moralidad como el egoísmo exigen que «yo obtenga lo mío», y que, independiente de lo que hagan los demás, parece que tanto yo como el mundo estaríamos mejor si yo no coopero. De hecho, puede que, en algunas circunstancias, el mejor resultado se obtenga incitando a los demás a cooperar mientras uno se abstiene de hacerlo ${ }^{22}$. El hecho de que yo conduzca por placer mi Chevy del 57, no supondrá en sí mismo una alteración del clima; del mismo modo que, si evito el hacerlo, no conseguiré que el clima se estabilice, y encima lograré con ello llegar tarde a las reuniones del Club Sierra. Este tipo de consideraciones lleva a mucha gente a utilizar sus Chevies para acudir a las reuniones del Club Sierra, contentos con la calidad de sus vidas aunque estén también preocupados por el futuro del planeta. Los países razonan de un modo similar. Ningún país tiene por sí mismo el poder de provocar o evitar el cambio climático. Por ello, los países no paran de hablar de lo importante que sería actuar, al tiempo que esperan que sean otros los que muerdan el anzuelo. Ya que tanto los individuos como los países pueden razonar de este modo, parece que el cálculo lleva a una espiral progresiva que conduce a la no cooperación ${ }^{23}$.

Esto debería llevarnos a renunciar al cálculo y la renuncia al cálculo implicaría la renuncia a la tesis de la condicionalidad. En lugar de tratar de construir una matemática moral para encontrar soluciones prácticas a los problemas de acción colectiva a gran escala, deberíamos más bien centrarnos en los aspectos inductores del comportamiento que no provienen del cálculo: los rasgos de carácter, las disposiciones, las emociones, y lo que llamaré «virtudes». Nuestra estrategia general, a la hora de afrontar el Cambio Medioambiental Global, debería ser, más bien, tratar de reducir nuestra contribución al mismo, independientemente del comportamiento de los demás, y es más fácil que consigamos hacer algo así mediante el desarrollo y transmisión de las virtudes adecuadas que mediante la mejora de nuestra destreza en el cálculo ${ }^{24}$.

12. Quizá esto pueda parecer el típico argumento contra el Utilitarismo de la Acción. El Utilitarismo de la Acción es la teoría que predispone a los agentes a realizar aquellas acciones que producirían los mejores resultados, en detrimento de otras acciones que el agente pudiera realizar. Hay filósofos que mantienen, conceptualmente, que los agentes que actúan según el Utilitarismo de la Acción no producirán los mejores resultados. Ya que ciertos

\footnotetext{
22 Discuto extensamente esta obizción en la Sección 19.

23 Para una más argumentos a favor de esta conclusión véase Donald Reagan, Utilitarianism and Cooperation, Nueva York, Oxford University Press, 1980.

24 No creo que nada de lo que aquí se dice se base en una caracterización particular del cálculo, como algo específicamente diferente a otras formas de cuantificación, tales como la valoración. Estoy en deuda con Jerrold Katz en lo que concierne a la discusión de este punto.
} 
bienes (p. ej., la cooperación, los gestos encomiables, las relaciones amorosas) no se encuentran al alcance de, o no pueden ser realizados por, agentes que siempre llevan a cabo la mejor acción ${ }^{25}$. Por ello, más que convertirnos en «utilitaristas directos» centrándonos tan sólo en las acciones, deberíamos ser «utilitaristas indirectos» interesados también en las motivaciones, las máximas, las políticas, las reglas o los rasgos de carácter.

En primer lugar, habría que aclarar que del hecho (si es que se da) de que ciertos bienes no estén al alcance de, o no sean realizados por, los utilitaristas de la acción, no se sigue, necesariamente, que el Utilitarismo de la Acción no pueda producir el mejor de los mundos. Puede que nuestro mundo esté construido de tal modo que el mejor estado de cosas no sea aquel en el cual se obtengan estos bienes, independientemente de lo importantes que nos parezcan, tomados de forma individual. Por ejemplo, el placer de beber un buen vino no está al alcance de o, en todo caso, no será obtenido por un abstemio, pero de ello no se deduce que la vida del abstemio no sea, al fin y al cabo, la mejor para él (es decir, la que produce mayor utilidad). Al renunciar al placer del vino, el abstemio puede liberar recursos (tanto financieros como energéticos) que le permitan obtener mayor utilidad de la que hubiese conseguido si no hubiese renunciado a tomar alcohol ${ }^{26}$.

Sin embargo, todo lo dicho hasta el momento es compatible con el rechazo del Utilitarismo de la Acción, aunque mi interés principal no sea, por el momento, el estudio detallado de las distintas versiones del Utilitarismo. Lo que realmente nos interesa es la psicología moral de un agente utilitarista al enfrentarse al Problema, y no la estructura conceptual de los valores. Convengo en que tal agente utilitarista no debería adoptar el Utilitarismo de la Acción como protocolo de decisión y convertirse en una constante máquina calculadora utilitarista. Una de las razones sería, evidentemente, que es imposible que tal propósito tenga éxito. Ya que, tanto desde un punto de vista cognitivo como motivacional somos criaturas débiles, con escasez de tiempo, de condiciones y de buena voluntad. Es nuestra propia naturaleza como criaturas biológicas y psicológicas la que entra en conflicto con la prescrip-

${ }^{25}$ Para un análisis relevante de alguna de estas cuestiones, véanse Regan, op. cit.; Allan F. Gibbard, «Rule Utilitarianism: Merely an Illusory Alternative?», Australasian Journal of Philosophy, 43, 1965, pp. 211-220; Robert M. Adams, «Motive Utilitarianism», Journal of Philosophy, 73, 1976, pp. 467-481, y Peter Railton, «Alienation, Consequentialism, and the Demands of Morality», Philosophy and Public Affairs, 13, 1984, pp. 134-171.

${ }^{26}$ Hay quien podría pensar que, a pesar de lo gráfico del ejemplo, está claro que una vida sin amigos nunca podría considerarse como maximizadora de la utilidad. Pero si asumimos que el comportamiento que maximiza la utilidad se asocia frecuentemente a la acción basada en razones independientes del agente individual, entonces resultará evidente que los estrechos lazos personales a menudo nos llevan a acciones que en modo alguno pueden considerarse optimizadoras de la utilidad. A pesar de ello, aunque esto fuera cierto, a muchos de nosotros nos iría peor si abandonásemos a todos nuestros amigos y nos dedicásemos a ser ciudadanos sin raíces, maximizadores de la utilidad. Para una discusión reciente de algunas de estas cuestiones, véase Elizabeth Ashford, «Utilitarianism, Integrity, and Partiality», The Journal of Philosophy, 97, 8, agosto de 2000, pp. 421-439. 
ción: «transfórmese usted en una constante máquina calculadora utilitarista y actúe en consecuencia». Nada conduce a pensar que tratar de vivir un sueño imposible vaya a producir mayores bienes que cualquier otro tipo de acción.

Esto parece tan obvio que a veces (perversamente) me pregunto quién inventó el Utilitarismo de la Acción, cuándo, dónde y con qué propósito. Como constructo teórico tiene su utilidad, pero mantener la idea de que un utilitarista moral debe defender una doctrina psicológicamente imposible para no incurrir en una inconsistencia, es no haber entendido el propio objetivo de la teorización moral ${ }^{27}$.

Está claro que Bentham y Mill no conocieron tal doctrina. Más bien aplicaron profusamente el principio de utilidad tanto a acciones como a motivaciones, reglas, principios, políticas, leyes, y a algunos casos más ${ }^{28}$. Y consideraron que, más que comenzar por el principio de utilidad y luego exigir que las personas se convirtieran en dioses o ángeles para poder cumplirlo, era mejor partir de una concepción determinada de la psique humana a la que adaptar tal principio. $\mathrm{Si}$, al cumplir con el principio de utilidad, pretendemos hacernos y hacer el mundo mejores, la conformidad de tal principio con la psicología humana es lo que hace de él un principio práctico. Bentham y Mill también eran conscientes del hecho de que las personas ven el mundo como una amalgama de partes heterogéneas: a veces debemos decidir entre distintas acciones, otras, entre distintas reglas o políticas. De hecho, a veces las acciones son la mejor expresión de las reglas y políticas y las reglas y políticas se implementan mediante acciones. Uno de los problemas más difíciles a los que nos enfrentamos como agentes morales es, precisamente, tratar de averiguar con exactitud a qué se aplica nuestra elección, en cada caso particular ${ }^{29}$. Está claro que un Utilitarismo de la Acción «de manual» no responde a nuestro problema, pero ¿qué otra cosa podríamos esperar? ${ }^{30}$.

\footnotetext{
27 No pretendo enfrentarme aquí a los que en sus investigaciones sobre las variedades del Utilitarismo distinguen entre Utilitarismo de la Acción y Utilitarismo de la Regla, sino que más bien estoy en desacuerdo con el modo en que tal distinción se ha convertido en un dogma que, incluso, se proyecta en la tradición anterior. Para un excelente estudio del espíritu original del Utilitarismo véase David Lyons, Forms and Limits of Utilitarianism, Oxford, Oxford University Press, 1965.

${ }^{28}$ Cf. el análisis de Michael Slote sobre Bentham en «Utilitarian Virtue,» se encuentra en P. French, T. Uehling Jr., y H. Wettstein (eds.), Midwest Studies in Philosophy Volume XIII Ethical Theory: Character and Virtue, Notre Dame, Indiana, University of Notre Dame Press, 1988, pp. 384-397.

${ }^{29}$ Onora O'Neill ha escrito con lucidez sobre el tema en el contexto de la ética kantiana op. cit., cap. 9. Véase, además, Stanley Cavell, The Claim of Reason, Nueva York, Oxford University Press, 1979 , pp. 263-267.

${ }^{30}$ En algún trabajo todavía inédito he intentado desarrollar una perspectiva sobre los objetivos de la moral teórica que creo están implícitos en la tradición filosófica del consecuencialismo moral. Hablo de estas ideas bajo la noción de «teoría moral naturalizada». Sobre los comienzos de esta teoría, véase «Method and Moral Theory», en P. Singer (ed.), A Companion to Ethics, Oxford, Basil Blackwell, 1991, pp. 476-487.
} 
En última instancia, el problema más profundo que suscita el Utilitarismo de la Acción es el mismo que el de cualquier punto de vista, por muy indirecto que sea, que se centre exclusivamente en motivaciones, o en reglas, o en cualquier otra cosa. Cualquiera de estas teorías sería «local», en el sentido de privilegiar un determinado «nivel» a partir del cual valorar las consecuencias de las posibles acciones que se nos ofrecen. Pero más que adoptar cualquiera de estos puntos de vista «locales» deberíamos ser utilitaristas «globales» y centrarnos en el nivel de valoración que, en una situación particular, nos permita hacer realidad el mejor estado de cosas posible ${ }^{31}$. Derek Parfit ha visto esta cuestión con claridad al afirmar que: «El Consecuencialismo se debe aplicar no sólo a las acciones y sus resultados, sino también a los deseos, disposiciones, creencias, emociones, al color de nuestros ojos, al clima y a todo lo demás. Más exactamente, el consecuencialismo debe aplicarse a cualquier cosa que pueda hacer que los resultados sean mejores o peores» ${ }^{32}$.

13. Quienes simpaticen con mi rechazo hacia cálculo utilitarista, pueden, sin embargo, pensar que, al acudir a las virtudes, me he arrojado en brazos de algo igualmente rechazable. Podría pensarse que hay otros lugares más seguros para los refugiados del cálculo utilitarista. Hay quien, por su parte, pensará que lo que nuestro Problema necesita es el poder coercitivo del estado y no ciudadanos virtuosos. Pero yo no creo que estos dos elementos sean mutuamente excluyentes. Los Estados legítimos sólo pueden surgir y mantenerse por medio de personas que actúen, razonen y respondan de un modo determinado. La mera existencia de un problema de acción colectiva no origina de inmediato una institución que lo solvente, independientemente de los valores y de los deseos de los agentes. De hecho, si no fuera así, ni siquiera tendríamos que enfrentarnos a nuestro Problema. Y aunque es verdad que no podemos resolver por completo nuestro Problema sin recurrir al poder estatal, esta consideración no es una respuesta, ni tampoco un punto a discutir, para las cuestiones que aquí se plantean.

Otros estimarán que la solución a nuestro Problema consiste en desarrollar motivaciones apropiadas de manera colectiva o compartida. Una versión de este punto de vista sostiene que los agentes individuales necesitan tener determinadas intenciones para poder «desempeñar su papel dentro de un acto colectivo» o para «verse a sí mismos como si estuvieran trabajando

${ }^{31}$ Esta distinción entre el utilitarismo global y local procede de la ingeniosa propuesta de Philip Pettit y Michael Smith, que distinguen entre consecuencialismo local y global y argumentan persuasivamente a favor de la superioridad del punto de vista general en su «Global Consequentialism», en B. Hooker, E. Mason y D. Miller (eds.), Morality, Rules and Consequences: a critical reader, Edinburgh University Press, 2000, pp. 121-133. Véase también Shelly Cagan, «Evaluative Focal Points», pp. 134-155 en el mismo volumen.

32 Op. cit., p. 25. 
colectivamente [sic] para promover el bienestar humano» ${ }^{33}$. Puede ser que las intenciones desempeñen un papel importante en la resolución de nuestro Problema, pero existen dudas sobre la identificación de la naturaleza exacta de tales intenciones: cómo surgen, qué tipo de personas las ostentan, y exactamente por qué y en qué circunstancias se adoptarían ${ }^{34}$. Nuestro estudio pretende también dar cuenta de estas cuestiones. A este respecto, nuestro análisis podría considerarse complementario o quizás una parte del proyecto de investigación sobre las intenciones compartidas o colectivas, consideradas éstas como solución a los problemas de acción colectiva ${ }^{35}$.

14. Ha llegado la hora de que diga algo más positivo sobre mi concepción de la virtud. La definición de Julia Driver podría servirnos como primera aproximación: una virtud moral es «un rasgo de carácter que sistemáticamente produce o da lugar al bien» ${ }^{36}$. Sin embargo, está claro que tal definición debería completarse para dar cuenta del hecho de que las emociones están íntimamente relacionadas con las virtudes ${ }^{37}$. Las emociones desempeñan, de hecho, un importante papel en el mantenimiento de los modelos de comportamiento que expresan la encarnación de virtudes tales como la lealtad, la valentía, la perseverancia y otras. Sin emociones que las

33 Para una comprensión del primer punto de vista, véase Christopher Kutz, Complicity: Ethics and Law for a Collective Age, Nueva York, Cambridge University Press, 2000, p. 11; Para el segundo aspecto, Murphy, op. cit., p. 96, nótese, sin embargo, que las observaciones de Murphy se hacen en el contexto de una investigación más amplia sobre el deber moral de caridad individual, bajo condiciones de un cumplimiento parcial). Otras reflexiones sobre las intenciones colectivas o compartidas fomentan la revisión de nuestra concepción sobre los agentes o sobre la intencionalidad, más que centrarse en el contenido de tales intenciones. Por ejemplo, John Searle sostiene que la acción colectivamente intencional sólo puede explicarse postulando una forma irreductible de intención que él denomina «el nosotros-intencional». En su Intentionality, Cambridge, Cambridge University Press, 1983, cap. 3. Para la discusión véase Kutz, op. cit., cap. 3.

34 Christopher McMahon en su Collective Rationality and Collective Reasoning, Nueva York, Cambridge University Press, 2001, afirma que la solución a los dilemas del prisionero (una clase de problemas estrechamente relacionada con el nuestro) estriba en considerarlos como simples problemas de coordinación. Sin embargo, en los dilemas del prisionero cada agente obtendrá su mejor resultado si no coopera, independientemente de lo que lo hagan los otros, mientras que no es éste el caso en los problemas de coordinación simple. Puesto que los dilemas del prisionero tienen una estructura diferente que los de coordinación simple, sería necesario apuntar algún motivo más claro y convincente para que nosotros pudiéramos contemplarlos desde la óptica sugerida por McMahon, y además debería proporcionarnos alguna explicación sobre el hipotético modo de ser de sus agentes para poder actuar según la forma elegida. En ausencia de tales informes, esta estrategia no parece tener más sentido que un cambio de planteamiento. Para un análisis más amplio véase Gerald Gaus, «Once More Unto the Breach, My Dear Friends, Once More», Philosophical Studies, 116, 2, noviembre, 2003, pp. 159-170, y Michael Weber, «The Reason to Contribute to Cooperative Schemes», 116, 2, Philosophical Studies, noviembre, 2003, pp. 171-181.

35 Los comentarios contenidos en este párrafo no pretender minimizar las contribuciones que McMahon, Kutz y otros han realizado al tratar de contestar a estas cuestiones, sino que pretenden señalar la necesidad de realizar trabajos más detallados al respecto.

36 Julia Driver, Uneasy Virtue, Nueva York, Cambridge University Press, 2001, p. 108.

37 Coincido en ello con Rosalind Hursthouse, On Virtue Ethics, Oxford, Oxford University Press, 1999, Parte II. Driver también analiza las relaciones entre virtudes y emociones, pero no tengo claro cuál sería su visión de este asunto. 
afiancen, es difícil imaginar que pudieran darse, en criaturas como nosotros, comportamientos tales como el cuidado de los hijos, la amistad y la colaboración doméstica ${ }^{38}$.

Pero, incluso si completásemos la definición de Driver con estas consideraciones, seguiría siendo excesivamente general, ya que existen diferentes concepciones de lo que significan expresiones tales como: «rasgo de carácter», «sistemáticamente», «producir» y «dar lugar a». Además, esta definición deja importantes cuestiones sin resolver, incluyendo las relativas a las relaciones entre las virtudes y la prosperidad de la humanidad, y las que se dan entre las propias virtudes. Sin embargo, no es necesario para nuestros fines contestar a estas preguntas. Lo que realmente nos importa es la diferenciación entre impulsos inductores de la acción basados en el cálculo y aquellos que no lo están, y denomino «virtudes» a un amplio conjunto de estos últimos ${ }^{39}$.

Algunos teóricos de la virtud no verán con buenos ojos este proyecto. Negarán incluso que el tipo de explicación que quiero dar sea siquiera una versión de la «ética de la virtud». Ya que mantienen que «lo fundamental en una ética de la virtud (...) es que considere las virtudes no simplemente importantes, sino en algún sentido básicas para la estructura moral» ${ }^{40}$. Quizás por deferencia hacia esta opinión, el objeto de mi investigación debería orientarse hacia la determinación del momento preciso en el que una teoría de la maximización de la utilidad precisa de una teoría de la virtud ${ }^{41}$.

15. Repasemos brevemente lo expuesto hasta el momento. Dada nuestra naturaleza y la naturaleza de nuestro Problema, la incondicionalidad ofrece más posibilidades para la maximización de la utilidad que la condi-

${ }^{38} \mathrm{Cf}$. Robert Frank que argumenta que la emociones promueven el egoísmo al resolver problemas de compromiso, en su Passions Within Reason, Nueva York, Norton, 1988.

39 Sin embargo, no todos los impulsos para la acción de tipo no calculador serían virtudes. Algunos son meras trivialidades, otros más bien vicios, y otros incluso estarían tan alejados de la noción tradicional de virtud que sería impensable, incluso bajo mi concepción, llamarlos virtudes.

40 James Griffin, Value Judgement: Improving Our Ethical Beliefs, Nueva York, Oxford University Press, 1996, p. 113. Véase también Michael Slote, From Morality to Virtue, Nueva York, Oxford University Press, 1992. Para una visión más flexible de lo que se considera una ética de la virtud véase Julia Annas, The Morality of Happiness, Nueva York, Oxford University Press, 1993.

4t Una objeción a la teoría de la virtud que comienza a ganar crédito es la que se deriva de algunos resultados de la psicología social que muestra que los factores contextuales son indicadores más fuertes de la conducta que el propio carácter individual. Para tales objeciones véase Gilbert Harman, «Moral Philosophy Meets Social Psychology: Virtue Ethics and the Fundamental Attribution Error», reimpreso en Explaining Value and Other Essays in Moral Philosophy, Oxford, Oxford University Press, 2000; and John Doris, «Persons, Situations, and Virtue Ethics», NOUS 32, 4, 1998, pp. 504-530, y en Lack of Character: Personality and Moral Behavior, Nueva York, Cambridge University Press, 2002. Puesto que no me encuentro comprometido con ninguna definición de las virtudes y mucho menos con la que las considera radicalmente internas a los individuos más que relativas al contexto, no creo que tales objeciones puedan aplicarse a las afirmaciones que aquí se ofrecen. 
cionalidad ${ }^{42}$. Y ello se debe a que la condicionalidad, probablemente, requiere del cálculo, pero no parece que el cálculo vaya a generar un comportamiento que maximice la utilidad. Por lo tanto, en lo relativo a nuestro Problema, los utilitaristas deberían empezar a tomarse en serio las virtudes.

El centrarnos en las virtudes, nos debería ayudar a regular y coordinar el comportamiento, a expresar el sentido y a contribuir a la constitución de la comunidad, en el espacio y en el tiempo, y a hacer surgir la empatía, la compasión, y la solidaridad entre los agentes morales.

16. El problema más serio que suscita la idea de que la incondicionalidad debería formar parte de una teoría utilitarista que tratara de responder a nuestro Problema, reside en que tal concepto se opone a un rasgo básico, extremadamente importante, aunque a veces poco mencionado, del Utilitarismo: el rechazo de la autocomplacencia. El carácter no autocomplaciente (Non-Complacency) del Utilitarismo implica que los modos de vida y los modelos de acción utilitaristas deberían responder dinámicamente a las circunstancias cambiantes, aprovechándose de las oportunidades singulares para producir la bondad, esforzándose siempre por mejorar. Veamos cómo, en primer lugar, esta no-autocomplacencia perjudica a algunas versiones del Utilitarismo Indirecto, y más a aquellas que pretenden producir juicios morales más afines a la moralidad del sentido común, que a aquellas que se derivan más directamente del Utilitarismo de la Acción. Las posturas que pretenden tal aproximación, nos pueden llevar, de hecho, a una complacencia moral que sería incompatible con cualquier teoría ética que pretenda producir los mejores resultados. Consideremos dos ejemplos.

Supongamos que soy un «utilitarista de la motivación» que actúa conforme a una serie de motivos que, supuestamente, producen más utilidad en total que cualquier otra serie de motivos que pudiera tener. Imaginemos que, en una situación hipotética, es evidente que puedo producir el máximo de bien actuando de un modo que resulta deleznable desde el punto de vista de la moralidad del sentido común y que tal acción es, además, incompatible con mi serie de motivaciones inicial. Un utilitarista concienzudo lucharía consigo mismo para ejecutar esta hipotética acción. Si falla, debería lamentar su fracaso - no porque el utilitarista deba valorar el remordimiento en sí, sino porque los sentimientos de culpa son una respuesta característica al fracaso en el cumplimiento del deber. Tales sentimientos de culpa pueden, además, provocar cierto endurecimiento en la conciencia de las personas de

\footnotetext{
42 Bernard Williams sostiene un punto de vista similar en su crítica a la teoría de los «dos niveles» de Hare; véase su «The Structure of Hare's Theory», en D. Seanor y N. Fotion (eds.), Hare and Critics, Oxford, The Clarendon Press, 1988, pp. 185-196. No obstante, mientras que Williams enfatiza la imposibilidad psicológica de vivir, a un tiempo, en el nivel «intuitivo» y en el «crítico», mí crítica se dirige expresamente a quienes se contentan con las reglas del sentido común cuando la moralidad les exige explícitamente que aspiren a realizar lo mejor.
} 
modo que, en el futuro, serán capaces de ejecutar tales hipotéticos actos, por muy repugnantes que puedan parecerles. Sin embargo, quien autocomplacientemente se consuela, sabiendo que sus motivos son los mejores que pudieran tenerse, sería reprobable desde un punto de vista utilitarista, ya que tal persona estaría actuando de un modo que sabe que no es el más correcto y ni siquiera intentaría hacerlo mejor.

Lo mismo podría decirse del caso de quien sabe que debería salvar a un extraño, antes que a su hermano, en un momento de tensión. Tal persona, en la medida en que sea un utilitarista, no puede sentirse realmente satisfecho diciéndose a sí mismo que, a fin de cuentas, en este caso, lo mejor es actuar a nivel «intuitivo» en vez de tratar de elevarse al nivel «crítico». En realidad, se comportaría del mismo modo que un piloto que prefiere volar a 30.000 pies en lugar de ascender hasta los 40.000 , consolándose por el hecho de estar actuando sobre la base de una buena regla de sentido común cuando, en realidad, se dirige directamente hacia un 747 cargado de pasajeros. Puede que, finalmente, no sea capaz de hacer lo correcto, pero debería hacer algo más que encogerse de hombros.

La no-autocomplacencia debería guiar al utilitarista a una mejora moral en dos sentidos. Primero, debería hacerle sensible al hecho de que las circunstancias cambian. El mejor juego de motivaciones en un mundo analógico, puede que no lo sea en un mundo digital. Un traslado desde Minnesota a California puede conllevar no sólo un cambio en el vestuario, sino también un juego de motivaciones óptimo diferente. Segundo, un utilitarista debería esforzarse constantemente en adecuar su juego de motivaciones de modo que su comportamiento sea cada vez más sensible a cada situación particular. Las motivaciones generales y las reglas del sentido común son tan sólo los puntos de partida para un agente utilitarista, pero no deberían ser el fin de su lucha interna por la mejora moral.

El problema es que la no-autocomplacencia, que a mí me parece tan importante pero que, en general, se subestima por parte de los utilitaristas indirectos, parece oponerse a la incondicionalidad, que es, a su vez, necesaria para dar cuenta de los problemas de acción colectiva a gran escala. De modo que, aunque las virtudes ofrecerían a los utilitaristas la posibilidad de concebir el comportamiento humano de una manera suficientemente inflexible para tratar los problemas de acción colectiva, fuera de este contexto de los problemas de acción colectiva los modelos de comportamiento flexible serán, generalmente, los más adecuados para maximizar la utilidad.

17. Una posibilidad para superar este escollo sería relajar nuestra exigencia de no-autocomplacencia, renunciando al Utilitarismo a favor del Consecuencialismo Progresivo. El Consecuencialismo Progresivo (¡¿sólo?!) nos exige producir un mundo cada vez mejor, en lugar del mejor mundo posible. Abandonar la exigencia de maximización del Utilitarismo en favor 
del deber diacrónico de mejorar el mundo ayudaría a aliviar, pero no a resolver, la tensión entre la incondicionalidad y la no-autocomplacencia. Ya que, mientras la incondicionalidad siga siendo relevante, se ocasionarán conflictos entre los rasgos de carácter relacionados con la misma y la exigencia de la no-autocomplacencia de que, al menos en algunas ocasiones, actuemos en contra de lo que estos rasgos, en principio, implicarían. Relajar la exigencia del objetivo final, disminuirá la frecuencia de estos conflictos, pero no los eliminará completamente ${ }^{43}$.

18. Otra posibilidad complementaria sería desarrollar una definición de las virtudes específica para cada dominio. En lo que se refiere al Cambio Medioambiental Global, los utilitaristas deberían, generalmente, comportarse como ecologistas inflexibles y virtuosos, pero, en la mayoría de los dominios, deberán ser flexibles calculadores.

El problema reside en que en esta vida los dominios no suelen mantenerse aislados. Supongamos que mi amigo Peter me pide que le lleve en coche a una reunión de Oxfam, pues es la única posibilidad que tiene de poder asistir $^{44}$. Sin embargo, yo soy un ecologista inflexible y virtuoso en lo que atañe al Cambio Medioambiental Global. Mi disposición al ecologismo hace que mi mano tiemble ante el solo pensamiento de la conducción que tendré que realizar, y por ello no podré satisfacer la petición de Peter de llevarle en coche a la reunión. Sin embargo, si fuera un calculador flexible y global, no me preocuparía tanto por saber en qué dominio específico se encuentran las utilidades implicadas. Si llevar a Peter a la reunión presentase mejores consecuencias que mi negativa, debería llevar a Peter. Parece, pues, que la incondicionalidad en el dominio del Cambio Medioambiental Global no contribuye a la realización de lo que es mejor en general.

Una posible respuesta a esta objeción sería decir que, en este caso, lo que debería hacer es calcular si debo o no calcular. Esta respuesta es al tiempo correcta e incorrecta. Como teóricos, deberíamos tratar de saber de antemano en qué casos el cálculo nos llevará a los resultados óptimos y en qué casos no, y ello nos obliga a calcular la utilidad del cálculo en diferentes dominios (como, de hecho, ya hicimos, de manera informal, en el párrafo anterior). Pero como agentes utilitaristas no deberíamos tratar de calcular si debemos o no calcular, pues ello iría en contra de la mera posibilidad de inculcar los rasgos de carácter que hacen de nosotros ecologistas virtuosos. En cualquier caso, tal cálculo de segundo orden nos amenaza con el fantas-

${ }^{43}$ Habría mucho que decir sobre el Consecuencialismo Progresivo. Algo más puede encontrarse en la ya mencionada entrada «Consequentialism», y también en Robert Elliot que examina esta idea en Faking Nature, Nueva York, Routledge, 1997, bajo el término «Consecuencialimo Meliorista".

44 Presupongamos que, en este caso, los beneficios y los perjuicios no traspasan dominios: los beneficios resultantes de que Peter asista a la reunión sólo atañen al alivio del hambre en el mundo y los perjuicios que ocasiona mi conducción se limitan a contribuir al Cambio Medioambiental Global. 
ma de una infinita petición de principio, a la vez que resulta forzado para nuestra capacidad psicológica ${ }^{45}$.

¿Qué debería entonces contestarle a Peter? Primero, los problemas del Cambio Medioambiental Global son tan serios y las virtudes ecologistas tan positivas, que su aplicabilidad debería ser muy amplia. Segundo, las virtudes ecologistas nunca estarían vigentes si cada una de sus manifestaciones tuviera que exponerse al test de la utilidad; así que, si pensamos de antemano que tener virtudes ecologistas producirá una maximización de la utilidad total, entonces no deberíamos exponer sus manifestaciones a dicho test (excepto en casos extremos, entre los cuales no parece encontrarse el ejemplo expuesto). No parece que les vaya a ir muy bien a Peter o a su reunión de Oxfam.

Por supuesto, el fantasma del cálculo reaparece en la expresión «excepto en casos extremos». Para un utilitarista, el compromiso con la incondicionalidad no debería ser tan extremo que descartase de antemano la posibilidad de una tal «cláusula de escape». Si éste fuera un caso extremo (supongamos que las vidas y el bienestar de toda la población de un país africano de tamaño medio dependiesen de que Peter asista a su reunión) y yo no me ofreciera a llevar a Peter, entonces yo no sería mejor que uno de esos compulsivos adoradores de la regla a quienes los utilitaristas gustan de criticar. ¿Pero, sin el cálculo, cómo puedo saber si realmente estoy o no ante un caso extremo?

Parte de la respuesta podría ser que a simple vista somos capaces de reconocer cuándo un caso es extremo: sencillamente los detectamos. Cuando una casa está en llamas, o cuando un niño grita, o cuando, ante nuestros ojos, se cometen atrocidades o nuestra civilización se ve amenazada, no necesitamos una matemática moral para comprender que los modelos de comportamiento que generalmente se consideran los mejores, quizá no se apliquen en este caso. Desde luego, también pueden darse ocasiones en las que el cálculo resultaría útil, precisamente, para ver que lo mejor sería abandonar los modelos de comportamiento que nos ofrecen las virtudes ecologistas. Pero, en tales ocasiones, el ecologista virtuoso no tendrá más remedio que renunciar al ideal de lo mejor, confiando, en cambio, en el poder de maximización de la utilidad de las virtudes ecologistas.

19. Se nos plantea una última objeción a la cual ya he hecho alusión brevemente (en la Sección 11). Si hay quien disfruta alterando el clima, destruyendo la capa de ozono, llevando a las especies a la extinción, y la causa verde se torna desesperada, entonces parece que me veo moralmente obligado a participar de tales diversiones. Un verdadero utilitarista no debería, con gran sacrificio personal, arar la nieve con su bicicleta mientras todos los demás le pasan zumbando en sus «utilitarios traga-gasolina». Si de todos modos vamos a destruir el mundo, entonces el utilitarista moralmente res-

45 Tales problemas se discuten ampliamente en la literatura económica bajo el concepto de «reglas de la detención óptima». Veáse, por ejemplo, el texto clásico de G. J. Stigler, «The Economics of Information», Journal of Political Economy, 69, 1961, pp. 213-225. 
ponsable tratará de pasarlo bien, sucumbiendo al mismo tiempo que lo hace el planeta. Si el mejor resultado general (la prevención del Cambio Medioambiental Global) queda fuera de mi alcance, y el peor resultado para mí sería llevar una vida miserable y apocada, intentando, en vano, obtener ese supuesto mejor resultado inaccesible, entonces el mejor resultado que, materialmente, puedo producir será aquel basado en un modo de vida desorbitadamente consumista. Pero si todos razonamos de este modo, podríamos llegar a la conclusión, no ya de que es aceptable vivir como un americano normal, sino incluso de que los utilitaristas se encuentran moralmente obligados a hacerlo. Esto me parece realmente escandaloso.

Hay aquí, en realidad, dos argumentos implicados. El primero se refiere al proceso de toma de decisión de un agente individual; el segundo afirma que lo descrito en el primero debería generalizarse a todos los agentes en la misma situación. Veamos primero el segundo de los argumentos. Éste juega con la pregunta equívoca de hasta qué punto el mejor resultado posible es, de hecho, accesible para el agente. Imaginemos un mundo con sólo dos agentes, Kelly y Sean. Desde el punto de vista de Kelly, parece claro, en principio, que Sean no va a comportarse de un modo ecológico, y, por lo tanto, lo mejor para Kelly será, igualmente, no hacerlo. Pero si Sean se encuentra en el mismo punto respecto de su propia decisión que Kelly, entonces no puede darse por hecho que Sean no vaya a comportarse ecológicamente, ya que eso es, justamente, sobre lo que aún está pensando. Si hay alguna razón para planteárselo como reflexión, entonces es que el comportamiento ecologista le resulta accesible, contrariamente a lo que asumimos al examinar el proceso decisorio de Kelly. Por ello la generalización, aparentemente inocente, del primer argumento introduce un equívoco que no estaba presente en su forma inicial individual ${ }^{46}$.

El primer argumento no debería confundirse con la que podría llamarse la Objeción de Nerón. Tal objeción puntualiza que, del mismo modo que Nerón tocaba el arpa mientras Roma se quemaba, un agente utilitarista debería tocar el arpa (o su equivalente funcional) mientras el Cambio Medioambiental Global devasta el planeta. Si encontramos moralmente abominable el comportamiento de Nerón, lo mismo habremos de declarar con respecto al equivalente utilitarista. Sin embargo, los ejemplos de Nerón y del utilitarista no son equivalentes en algunos aspectos relevantes. Lo que repugna de la imagen de Nerón tocando el arpa ante el incendio de Roma es que, probablemente, fue él quien provocó materialmente el fuego, o al menos quien podría haber ordenado su extinción. En lugar de tratar de hacer lo mejor en una mala situación, lo que hizo fue directamente

46 Existen modos alternativos de retomar el segundo argumento considerándolo en términos probabilísticos, pero no puedo referirme aquí esa posibilidad. Para la comprensión de un buen número de estos casos han resultado fundamentales las conversaciones que he mantenido con Scott (Drew) Schroeder. 
crear una mala situación ${ }^{47}$. Esto es algo que el Utilitarismo prohíbe expresamente.

Veamos un planteamiento algo mejor del primer argumento. Debemos seguir teniendo en cuenta que, en lo que se refiere al comportamiento relevante para el Cambio Medioambiental Global, lo que perseguimos es un comportamiento ecologista inflexible, aun cuando nunca debería serlo demasiado. Supongamos que existe un umbral de cooperación que debe superarse si queremos evitar el Cambio Medioambiental Global. Si este umbral no va a superarse en ningún caso, independientemente de lo que yo haga, entonces lo mejor para mí sería actuar de otro modo que siendo un ejemplo de virtud ecologista. Pero el cálculo sobre si tal umbral será o no alcanzado parece oponerse a las ventajas de la inflexibilidad, supuestamente encarnada por las virtudes ecologistas. Además, si el cálculo da como resultado que yo debería comportarme de forma medioambioentalmente destructiva, entonces estaría en contradicción con lo que sabemos positivamente que debe dictarnos la moralidad. Es, precisamente, por razones de este tipo que hay quien piensa que cambiar el enfoque de las acciones a los caracteres no resuelve los problemas de la acción colectiva.

El hecho de que el cambio de enfoque de las acciones a los caracteres tenga o no éxito en la solución del problema, dependerá exactamente de cuál sea éste. Si el Utilitarismo implicase realmente que lo que debo hacer es lanzar botellas de tequila por la ventana mientras voy al trabajo en mi «utilitario», este resultado, con todo, no sería más espantoso que algunas otras posibilidades que podrían deducirse del Utilitarismo en otras situaciones igualmente hipotéticas: por ejemplo, en algunos casos puede que esté moralmente obligado a ahorcar a gente inocente, a torturar a prisioneros, o a bombardear ciudades. La razón por la que estas objeciones no hacen mella en el que ya es utilitarista, es debido a que, por hipótesis, en todos estos casos se presupone que mi horrible actuación contribuirá a producir el mejor mundo posible ${ }^{48}$. Si el mundo está en un estado tan lamentable que ahorcar a personas inocentes constituye una mejora del estado de cosas, no es seguramente por culpa de la propia teoría utilitarista. Por otro lado, si no se supone que tal acción es, en este sentido, óptima, entonces el crítico está de nuevo cometiendo el sempiterno error (comentado anteriormente) de pretender mostrar que el Utilitarismo mueve a los agentes a actuar de un modo tal que, realmente, haría al mundo peor o no tan bueno como podría ser. Como hemos visto, el Utilitarismo no puede nunca implicar tal cosa.

${ }^{47}$ El locus classicus de esta imagen de Nerón procede de Gibbon, pero las recientes investigaciones sugieren que Nerón ha cargado injustamente con todas las culpas: parece que él no fue el autor material del incendio, ni tampoco está claro que el suceso le resultase indiferente. Véase, T. Griffin, Nero: The End of a Dynasty, Londres, Batsford, 1984.

${ }_{48}$ R. M. Hare propone un argumento similar con relación a la esclavitud; véase "What is Wrong With Slavery», Philosophy and Public Affairs, 8, 1979, pp. 103-121. 
Si el mejor resultado fuese, en realidad, algo inaccesible para mí, entonces no sería completamente inverosímil suponer que tenga el deber de convertir en buena una mala situación ${ }^{49}$. Cuando yo era niño, crecí en un vecindario que, con toda seguridad, habría sido un «objetivo prioritario» de haber estallado una guerra nuclear entre los americanos y los rusos. A menudo nos planteábamos seriamente la siguiente cuestión. Supón que sabes que Ellos ya han lanzado sus misiles y que Nosotros ya hemos tomado represalias (o viceversa), y que en veinte minutos el planeta se desintegrará. ¿Qué tenemos que hacer? ${ }^{50}$. La idea de que deberíamos disfrutar de lo que nos queda de vida puede que no sea la única respuesta plausible a esta cuestión, pero seguramente no es tan inverosímil. Pienso que lo que muchas personas encuentran de chirriante en esta respuesta es la idea de que tenemos el deber de disfrutar de la vida en tal situación extrema. Puede que haya quien esté de acuerdo en que sería moderadamente aceptable el hacerlo, pero encuentre, sin embargo, escandaloso que la moralidad se entrometa hasta ese punto en el advenimiento del fin del mundo. Y la cosa no mejora si aplicamos el razonamiento al caso de creer que, realmente, la causa ecologista se ha vuelto desesperada. Una cosa es decir que está permitido o que es perdonable abandonar nuestros compromisos ecologistas en tales circunstancias extremas y otra, completamente distinta, decir que tenemos el deber explícito de alistarnos en las filas del enemigo, y así disfrutar de las actividades que, precisamente, destruyen los elementos de la naturaleza que nos son más queridos ${ }^{51}$.

Toda esta objeción se basa en la presuposición de que podríamos encontrarnos en circunstancias de saber, con certeza, que vivir de acuerdo con valores ecologistas va a ser completamente inútil, y que nosotros disfrutaremos más abandonándonos a los placeres consumistas. Bajo tales supuestos improbables, el crítico tiene razón en afirmar que el Utilitarismo nos exigiría pasarnos al bando de los expoliadores medioambientales. En realidad, este caso no nos muestra nada nuevo. No es sino otro ejemplo más del «exigen-

49 A este respecto, disiento de la opinión de Christopher Kutz, op. cit., pp. 124-132, que rechaza lo que él llama «consecuencialismo» porque no consigue explicar por qué está mal tomar parte en una mala acción que, en todo caso, va a producirse. Para una visión alternativa a la de Kutz, véase Frank Jackson, «Group Morality», en Philip Pettit y otros (eds.), Metaphysics and Morality: Essays in Honour of J.J. C. Smart, Oxford, Basil Blackwell, 1987. Las ideas sobre los casos sobredeterminados se desarrollan por cauces diversos, dependiendo de los casos particulares y de cómo sean descritos; no nos podemos hacer cargo en este escrito de un tratamiento completo de este problema. En la comprensión de este punto, me ha resultado muy provechosa la lectura del trabajo inédito de Frank Jackson y Dan Moller.

so Esta pregunta se asemeja a aquella a la que muchos de nosotros podríamos tener que enfrentarnos en el futuro (o, quizás, ahora): ¿Qué debería hacer, si sé que voy a morir en un plazo determinado? Por supuesto, no deberíamos dar por hecho que la pregunta concreta que nos hacíamos en mi juventud haya dejado de ser relevante.

51 Esta consideración se asemeja a la observación realizada por C. S. Lewis, que afirmaba que cuando alguien está a punto de ser arrastrado por una cascada no tiene por qué entonar, en ese preciso momento, cánticos de alabanza a los dioses del río. 
tismo» del Utilitarismo, o si se prefiere, de cómo el Utilitarismo mantiene a nuestros «proyectos fundamentales» (y, por tanto, a nuestra integridad) rehenes de circunstancias que quedan fuera de nuestro control ${ }^{52}$.

No es mi propósito llevar a cabo una defensa del Utilitarismo más allá de su aplicabilidad como un programa de investigación plausible. Sin embargo, seguramente es por todos conocido que el Utilitarismo puede exigir de nosotros que abandonemos modelos de comportamiento usuales y que nos resultan entrañables para hacer aquello que produce lo mejor. Desde luego, esto no es en absoluto fácil y la mayoría de nosotros, en la mayoría de las ocasiones, no conseguirá hacer lo correcto (¡nadie dijo que fuera fácil ser un utilitarista!). Pero nuestra incapacidad para hacer lo correcto, no debería utilizarse como crítica hacia la idea moral de que se debe hacer lo mejor, del mismo modo que la tendencia humana a la violencia no debería hacernos renunciar a la paz como un valor moral estimable. $\mathrm{O}$ al menos eso parece a primera vista.

Sin embargo, el punto que más quiero destacar es el siguiente. Mi interés no se dirige hacia una realidad alternativa o hacia mundos posibles, sino hacia los hechos de este mundo que son relevantes para nuestros objetivos. Lo que me interesa, aquí y ahora, es estudiar cómo un agente utilitarista debería responder al problema del Cambio Medioambiental Global. El Cambio Medioambiental Global no se asemeja al fenómeno de una colisión interplanetaria inminente, pues ésta cae por completo fuera de nuestro control. Tampoco se trata de un fenómeno de «todo o nada». Colectivamente, podemos prevenir o minimizar diferentes aspectos del Cambio Medioambiental Global, y un agente individual puede influir en el comportamiento colectivo de varios modos. El comportamiento de un determinado individuo en la producción y el consumo impacta directamente en su propio entorno ambiental, así como en aquellas características de su comportamiento que sirven como ejemplo y como modelo a los demás ${ }^{53}$. Es bien sabido que puede que uno nunca sepa cómo van a acabar los proyectos a largo plazo, y ni siquiera conozca qué resultados reales ha obtenido al motivar o enrolar a otros en los mismos; pero estas razones podrían aducirse tanto en favor del optimismo como del pesimismo. Tampoco es cierto que el estilo de vida ecologista tenga que ser necesariamente desgraciado ${ }^{54}$. Incluso si al final,

${ }^{52}$ Esta última objeción al Utilitarismo fue un tema constante en el trabajo de Bernard Williams, y ha generado una enorme literatura. Comenzando por el famoso caso de Jim y los indios, véase Bernard Williams, «A Critique of Utilitarianism», en J. J. C. Smart and Bernard Williams, Utilitarianism: For and Against, Cambridge, Cambridge University Press, 1973, pp. 77-150. Para una inusual discusión en torno a la objeción del «exigentismo», véase Murphy, op. cit., caps. 2-3.

53 Véase Ziva Kunda, Social Cognition: Making Sense of People, Cambridge MA, The MIT Press, 1999, pp. 501-506.

${ }_{54}$ Contrariamente a lo que uno podría pensar leyendo los periódicos, las relaciones entre los informes subjetivos sobre el bienestar y las medidas económicas (como la renta per capita o el PIB) son ambiguas y complejas. Una vía sencilla para introducirse en estas cuestiones puede ser la página de Ed Diener, uno de los investigadores más importantes en el campo del bienestar subjetivo (http://www.psych.uiuc.edu/ ediener/). 
los valores del ecologismo no prevalecieran, hay consuelo y satisfacción en vivir de acuerdo con sus ideales ${ }^{55}$. Tomando todo esto en consideración, parece quedar claro que los verdaderos agentes utilitaristas, aquí y ahora, deberían tratar de impedir o al menos minimizar el Cambio Medioambiental Global antes que celebrar su advenimiento.

Hay que señalar que, hasta el momento, no existe ningún algoritmo capaz de diseñar el agente utilitarista óptimo ${ }^{56}$. Tampoco existe ningún algoritmo para construir la perfecta Constitución que impida, por ejemplo, el gobierno de las mayorías cuando deba, y no impida su expresión cuando no deba hacerlo ${ }^{57}$. Sin embargo, existen tanto buenas como malas personas y constituciones, y sabemos identificarlas cuando las vemos. Quizás fuera agradable disponer de un cálculo que pudiéramos aplicar a las constituciones y al carácter, pero en ausencia de éste, podemos todavía seguir viviendo y organizando nuestras sociedades. Sé que estas respuestas no pueden satisfacer a quienes están explícitamente interesados en la lógica de la acción colectiva o a quien cree que cada pregunta posee su respuesta exacta. Pero creo que son ellos quienes deberían acercarse a quienes como yo estamos interesados en la psicología moral de la acción colectiva y estamos dispuestos a aceptar la idea de Aristóteles de que la especulación teórica nunca podrá aislarse completamente de la sabiduría práctica.

20. A pesar de los distintos rompecabezas y complejidades con que hasta ahora nos hemos ido encontrando, hemos tratado de mostrar que, en lo que se refiere al Cambio Medioambiental Global, los utilitaristas deberían ser teóricos de la virtud. Aunque no pretendo confeccionar una lista completa de las virtudes que los utilitaristas deberían tratar de desarrollar e inculcar, ofreceré a continuación un bosquejo breve y provisional de lo que podrían llamarse «virtudes ecologistas» ${ }^{58}$. Nuestro objetivo no es tratar de construir

\footnotetext{
55 Una forma de desarrollar esta cuestión en el terreno de la decisión teórica puede seguirse en Alexander Schuessler, en A Logic of Expressive Choice, Princeton, Princeton University Press, 2000 , en donde distingue «expresiones» y «resultados» de los valores sujetos a elección. Esta distinción puede además ayudar a explicar nuestras intuiciones en los casos de daños sobredeterminados (mencionados en la nota 49). La máxima hondura filosófica en esta cuestión la he encontrado en Thomas Hill Jr., «Symbolic Protest and Calculated Silence», Philosophy and Public Affairs, 9, Fall, 1979, pp. 83-102, Aunque Hill centra la cuestión en los actos maliciosos y en las prácticas aparentemente inocentes que se hallan implicadas en el Cambio Medioambiental Global.

56 David Lyons se mueve en un punto de vista similar cuándo habla de la «opacidad moral» y de la «ambiguiedad moral» del utilitarismo (en «The Moral Opacity of Utilitarianism», en Hooker y otros, Morality, Rules, and Consequences), aunque no estoy seguro de qué conclusión quiere extraer de su análisis.

57 Jon Elster ha hablado extensamente sobre la analogía entre el pre-compromiso, individual y colectivo, y el autocontrol, sobre todo recientemente en Ulysses Unbound, Nueva York, Cambridge University Press, 2000.

58 James Griffin advierte, op. cit., p. 106, que el problema del cálculo regresa aquí para atormentarnos, en la medida en que parece que para identificar las virtudes tenemos que ser capaces de determinar con exactitud aquellos rasgos del carácter que promueven la utilidad. En cierta medida, a este problema se deberá enfrentar toda teoría que se tome en serio la investigación tanto del carácter como de las consecuencias.
} 
un descripción completa del agente moral utilitarista ideal, sino sólo dar algunos ejemplos de cómo deberíamos concebir las virtudes ecologistas que tal hipotético agente debería encarnar ${ }^{59}$. Existe poca literatura sobre este asunto, pero gran cantidad de experiencia y reflexión sobre los modos de vida ecologista que nos puede servir de base ${ }^{60}$.

De manera abstracta, podríamos empezar diciendo que las virtudes ecologistas serán aquellas que los utilitaristas deberían tratar de encarnar y de inculcar en los demás, dada la realidad del Cambio Medioambiental Global. De manera práctica, parece claro que las virtudes ecologistas deberían tratar de moralizar los comportamientos relacionados con la reproducción y el consumo. Según afirma Alan Durning: «cuando la mayoría de la gente, al ver un coche grande, piense en la polución atmosférica que provoca, antes que en la posición social que revela, habremos alcanzado la ética medioambiental. De manera semejante, cuando la mayoría de la gente se enfade al ver envoltorios exagerados, productos desechables, o ante la apertura de un nuevo centro comercial, porque los consideren crímenes contra sus nietos, el consumismo comenzará su retirada ${ }^{61}$.

21. Las virtudes ecologistas pueden clasificarse en tres categorías: las que reflejan valores tradicionales; las que se basan en valores tradicionales pero añaden algo a su contenido; y las que reflejan nuevos valores. Denomino estas tres vías para la identificación de virtudes, la conservación, la rehabilitación y la creación. Consideraré cada una por separado, ofreciendo algunos ejemplos provisionales de virtudes ecologistas que podrían incluirse en las distintas categorías mencionadas.

Thomas Hill Jr. ofrece un ejemplo que se correspondería con la vía de la conservación ${ }^{62}$. Argumenta que el ideal, ampliamente compartido, de la «humildad» debería llevarnos al amor por la naturaleza. Afirma que la indiferencia hacia la naturaleza «probablemente refleja ignorancia, presunción, o una carencia de autoestima que debemos vencer siendo suficientemente

${ }^{59}$ Una descripción completa del agente utilitarista ideal enfrentado a nuestro Problema tendría que incluir asimismo sus vicios, tal como me hizo observar Corliss Swain. Es más, es posible que algunos vicios como el de la avaricia, sean tan importantes para explicar y motivar tal comportamiento, como las virtudes que he considerado.

${ }^{60}$ Para iniciarse en la literatura sobre la teoría de las virtudes ecologistas, véase «Philip Cafero, «Thoreau, Leopold, and Carson: Toward an Environmental Virtue Ethics», Environmental Ethics, 23, 1, primavera, 2001, pp. 3-17; Geoffrey B. Frasz, «Environmental Virtue Ethics: A New Direction for Environmental Ethics», Environmental Ethics, 15, 1993, pp. 259-274; Lisa Newton, Ethics and Sustainability: Sustainable Development and the Moral Life, Upper Saddle River NJ, Prentice-Hall, 2003, y Louke van Wensveen, Dirty Virtues: The Emergence of Ecological Virtue Ethics, Amherst NY, Humanity Books, 1999.

${ }^{61}$ Alan Durning, How Much Is Enough? The Consumer Society and the Future of the Earth, Nueva York, W. W. Norton \& Company, 1992, p. 138.

62 «Ideals of Human Excellence and Preserving the Natural Environment», reimpreso en Lori Gruen y Dale Jamieson (eds.), Reflecting on Nature: Readings in Environmental Philosophy, Nueva York, Oxford University Press, 1994, pp. 98-110. La páginas reseñadas pertenecen a esta edición. 
humildes» ${ }^{63}$. Una persona que posea la necesaria humildad no destruirá bosques de secoyas (por ejemplo) incluso aunque parezca que el criterio de utilidad apoya tal comportamiento. Si lo que afirma Hill es correcto, la humildad es una virtud que debería ser conservada por los ecologistas. La templanza podría ser una buena candidata como ejemplo para la vía de la rehabilitación. Considerada tradicionalmente como una de las cuatro Virtudes Cardinales, la templanza se orienta en principio a contrarrestar la akrasía o incontinencia del agente. Pero la templanza puede entenderse también de forma más genérica como la virtud que acompaña al dominio de uno mismo y a la moderación. Podríamos rehabilitar la templanza como la virtud ecologista encargada de acentuar la importancia de la reducción del consumo.

Nuestra opción dentro de la categoría de la Creación sería la virtud que podríamos llamar la consciencia. La mayoría de nuestros comportamientos ecológicamente destructivos son irreflexivos, incluso mecánicos. Para poder mejorar nuestro comportamiento tenemos que ser capaces de comprender las consecuencias remotas, tanto en el sentido espacial como temporal, de nuestras acciones. Un ecologista virtuoso, cuando compra una prenda de vestir (por ejemplo), debería sentir que asume en sí el peso moral tanto de su proceso de producción como de los problemas que acarree la eliminación de la misma, una vez agotada su utilidad. De este modo, se sentirá responsable del cultivo del algodón, del impacto ambiental que provoca el proceso del teñido, de los gastos de energía derivados del transporte, etc. Si somos conscientes de todos estos extremos, nuestra toma de decisiones se verá reforzada por el hecho de ser, al tiempo, la expresión un rasgo de carácter moralmente loable que más bien escasea en nuestros tiempos y al que se suele prestar poca atención ${ }^{64}$.

Aunque hasta ahora hayamos mencionado tan sólo a los agentes individuales con sus virtudes, es fácil apreciar que también las instituciones desempeñan un importante papel en el desarrollo de las mismas. La literatura generada por la teoría de la virtud ha tratado ampliamente varias de estas tareas institucionales (p. ej., la inculcación, el estímulo). Sin embargo, debemos darnos cuenta de que el modo en que las sociedades y las economías se organizan puede, igualmente, imposibilitar el desarrollo de algunas virtudes. Por ejemplo, en una economía globalizada, sin la necesaria transparencia informativa, será sumamente difícil para un agente hacerse cargo de los

${ }^{63}$ Ibid., p. 108.

${ }^{64}$ El cooperativismo podría ser otra de las características relevantes de los agentes que podrían ayudarnos a resolver nuestro Problema (así como otros los problemas de acción colectiva, en general). Sorprendentemente, los teóricos de la virtud, tanto antiguos como modernos, han prestado muy poca atención a este rasgo (Hume sería la excepción). Quizás el cooperativismo pueda ser otro buen candidato a virtud en la categoría de Creación, o quizá el cooperativismo no sea siquiera una virtud, sino un rasgo que poseen los que ya disponen de un sólido conjunto de virtudes. Para el análisis de la importancia del cooperativismo para la moralidad, véase Robert A. Hinde, Why Good is Good: The Sourses of Morality, Londres, Routledge, 2002. 
efectos remotos de sus acciones, y mucho menos responsabilizarse de ellos ${ }^{65}$. En una sociedad de este tipo, será difícil desarrollar la virtud de la consciencia.

22. Finalmente, querría apuntar algunas conclusiones. Si mi argumentación es correcta, el contraste que habitualmente se establece entre el Utilitarismo y la teoría de la virtud quedaría en entredicho. En principio, el Utilitarismo puede encarnar cualquier conducta, ya que implica que nosotros deberíamos mentir, engañar, robar y aun apropiarnos de Aristóteles, si con ello vamos a ocasionar los mejores resultados. En algunas situaciones y en algunos mundos posibles, lo mejor se obtendría centrándonos, con la mayor precisión posible, en los actos individuales. En otras situaciones y otros mundos, convendría, más bien, ocuparse de los rasgos de carácter. El caso del Cambio Medioambiental Global nos ha llevado hacia el estudio de los caracteres, puesto que, como hemos visto, los mejores resultados se obtienen, generalmente, al disociar nuestro comportamiento del de los demás. Por ello, en este caso y en este mundo, los utilitaristas deberían ser teóricos de la virtud ${ }^{66}$.

La moraleja principal del artículo sería la siguiente: filosóficamente, debemos tratar de averiguar en qué casos los utilitaristas deberían ser teóricos de virtud, y no si, en general, deberían serlo o no. En el terreno práctico, lo que debemos hacer es construir un catálogo de virtudes ecologistas e indicar el mejor modo de inculcarlas. Quizá haya quien considere que todo esto no es más una «obsesión» suscitada por nuestra adhesión una teoría moral concreta, pero, en mi opinión creo que no es mucho pedir que los filósofos se encarguen de estas tareas prácticas en lugar de seguir con sus especulaciones mientras los seres humanos están causando la transformación más profunda que ha sufrido la Tierra en los últimos cincuenta millones de años ${ }^{67}$.

${ }^{65}$ La literatura sobre este tema es cada vez más abundante. Véase, por ejemplo, David C. Korten, When Corporations Rule the World, West Hartford CT, Kumarian Press, 1995.

${ }_{65}$ Roger Crisp llega a una conclusión similar en «Utilitarianism and the Life of Virtue», Philosophical Quarterly, 42, 1992, pp. 139-160.

${ }^{67}$ Las primeras versiones de este artículo se presentaron en varias conferencias impartidas en: la «Conferencia sobre la Reconsideración del Utilitarismo» en Nueva Orleáns, Louisiana; el Departamento de Filosofía de la Universidad de la Edimburgo; la Facultad de Filosofía de la Universidad de Oxford; el Centro para los Valores y la Política Social de la Universidad de Colorado; la reunión de la Asociación Austral-asiática de Filosofía que tuvo lugar en Sydney; la Conferencia Internacional de Ética Aplicada de Universidad China de Hong Kong; el Departamento de Filosofía de la Universidad de Wisconsin, Madison; la Reunión Mensual sobre Filosofía Moral de Minnesota; el Programa de Filosofía del Centro de Postgrado de la Universidad de la Ciudad de Nueva York y el Departamento de Filosofía de la Universidad de Yale. Estoy sinceramente agradecido al público de todas estas conferencias por las interesantes discusiones que en ellas se suscitaron. Agradezco especialmente a David Copp, Roger Crisp y James Griffin sus útiles comentarios. El origen de este artículo se remonta a una conversación mantenida hace mucho tiempo con Barbara Herman sobre el alcance y dominio de la moralidad; y aunque nada de lo aquí se dice pueda dirimir definitivamente nuestras diferencias teóricas, tal como se manifestaron en aquella ocasión, quiero mostrarle mi agradecimiento por hacerme pensar tanto y durante tan largo tiempo sobre este problema. 